\title{
Retraction Note: The role of remote sensing for mountain soil characteristics and rural asset allocation
}

\author{
Huibo Wang ${ }^{1}$
}

Published online: 6 December 2021

C) Saudi Society for Geosciences 2021

Retraction Note: Arabian Journal of Geosciences (2021) 14: 1156 https://doi.org/10.1007/s12517-021-07461-0

The Editor-in-Chief and the Publisher have retracted this article because the content of this article is nonsensical. The peer review process was not carried out in accordance with the Publisher's peer review policy. The author has not responded to correspondence regarding this retraction.

The original article can be found online at https://doi.org/10.1007/ s12517-021-07461-0.

Huibo Wang

whb1225@buaa.edu.cn

1 School of Economics and Management, Beihang University, Beijing 100191, Beijing, China 